\title{
A force field for tricalcium aluminate to characterize surface properties, initial hydration, and organically modified interfaces in atomic resolution $\uparrow$ \\ Cite this: DOI: $10.1039 / \mathrm{c} 4 \mathrm{dt} 00438 \mathrm{~h}$
}

Received 11th February 2014, Accepted 22nd April 2014

DOI: $10.1039 / \mathrm{c} 4 \mathrm{dt} 00438 \mathrm{~h}$

www.rsc.org/dalton
Ratan K. Mishra, ${ }^{a}$ Lucia Fernández-Carrasco, ${ }^{\mathrm{b}}$ Robert J. Flatt*a and Hendrik Heinz ${ }^{\star c}$

Tricalcium aluminate $\left(\mathrm{C}_{3} \mathrm{~A}\right)$ is a major phase of Portland cement clinker and some dental root filling cements. An accurate all-atom force field is introduced to examine structural, surface, and hydration properties as well as organic interfaces to overcome challenges using current laboratory instrumentation. Molecular dynamics simulation demonstrates excellent agreement of computed structural, thermal, mechanical, and surface properties with available experimental data. The parameters are integrated into multiple potential energy expressions, including the PCFF, CVFF, CHARMM, AMBER, OPLS, and INTERFACE force fields. This choice enables the simulation of a wide range of inorganic-organic interfaces at the 1 to $100 \mathrm{~nm}$ scale at a million times lower computational cost than DFT methods. Molecular models of dry and partially hydrated surfaces are introduced to examine cleavage, agglomeration, and the role of adsorbed organic molecules. Cleavage of crystalline tricalcium aluminate requires approximately $1300 \mathrm{~mJ} \mathrm{~m}^{-2}$ and superficial hydration introduces an amorphous calcium hydroxide surface layer that reduces the agglomeration energy from approximately $850 \mathrm{~mJ} \mathrm{~m}^{-2}$ to $500 \mathrm{~mJ} \mathrm{~m}^{-2}$, as well as to lower values upon surface displacement. The adsorption of several alcohols and amines was examined to understand their role as grinding aids and as hydration modifiers in cement. The molecules mitigate local electric fields through complexation of calcium ions, hydrogen bonds, and introduction of hydrophobicity upon binding. Molecularly thin layers of about $0.5 \mathrm{~nm}$ thickness reduce agglomeration energies to between 100 and $30 \mathrm{~mJ} \mathrm{~m}^{-2}$. Molecule-specific trends were found to be similar for tricalcium aluminate and tricalcium silicate. The models allow quantitative predictions and are a starting point to provide fundamental understanding of the role of $C_{3} A$ and organic additives in cement. Extensions to impure phases and advanced hydration stages are feasible.

\section{Introduction}

Concrete is a heterogeneous and complex multi-scale material "par excellence". ${ }^{1}$ An enormous annual production of 1.6 billion tons of cement, ${ }^{2,3}$ however, also contributes $5-8 \%$ of worldwide $\mathrm{CO}_{2}$ emissions. ${ }^{4,5}$ In addition, particle grinding consumes $26 \%$ of the total required electrical energy. ${ }^{3}$ The use of less energy-intensive, supplementary cementitious materials can lower carbon dioxide emissions, and small amounts of organic additives are known to reduce electricity consumption

\footnotetext{
${ }^{a}$ Department of Civil, Environmental and Geomatic Engineering, ETH Zurich, CH-8093 Zürich, Switzerland. E-mail: flattr@ethz.ch

${ }^{b}$ Department of Architectural Technology I, Universitat Politècnica de Catalunya, 08028 Barcelona, Spain

${ }^{c}$ Department of Polymer Engineering, University of Akron, Akron, OH 44325, USA. E-mail:hendrik.heinz@uakron.edu

$\dagger$ Electronic supplementary information (ESI) available: Additional figures, tables, full computational details, limitations, and opportunities. See DOI: $10.1039 / \mathrm{c} 4 \mathrm{dt} 00438 \mathrm{~h}$
}

during grinding as well as to increase grinding efficiency. ${ }^{6-8}$ Nevertheless, rational design of cement properties such as particle cleavage, hydration reactions, setting kinetics, and strength development with modified composition remains a key challenge facing the industry. ${ }^{9}$ The basic chemistry and physics of grinding and hydration from nanoscale to macroscale still poses many open questions. In particular, nanometerscale phenomena elude direct observation and require new methods of control including guidance by simulation. .,10 $^{5}$

A wide array of characterization techniques has thus been applied to cement phases, for example, X-ray diffraction (XRD), small angle neutron scattering (SANS), in situ imaging by transmission electron microscopy (TEM), atomic force microscopy (AFM) and nanoindentation, zeta potential measurements, nuclear magnetic resonance spectroscopy (NMR), infrared (IR), and Raman spectroscopy. ${ }^{11-18}$ In addition, models and simulations have been developed to enhance understanding and materials design. ${ }^{8,10,19-30}$ Such approaches include electronic structure calculations, 
molecular dynamics, Monte Carlo, and continuum methods, as well as multi-scale combinations of methods.

Quantum-mechanical techniques such as density functional theory (DFT) can provide insight into the kinetics and thermodynamics of cement hydration at the scale of chemical bonds. $^{21,22,26,28}$ However, the methods cannot reach beyond hundreds of atoms and picosecond time scales in good accuracy. Simulations of actual nanocrystals, aqueous interfaces, surface reactions, selective adsorption of organic modifiers, and assembly of nano-objects thus require classical molecular

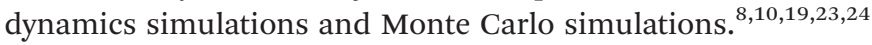
Such models on the basis of force fields retain all-atomic detail for up to a million atoms and access time scales up to microseconds. Simulation of yet larger systems of micrometersize particles, grinding, sedimentation, and aggregate mechanical properties is feasible using coarse-grain and continuum methods. ${ }^{27,31,32}$

To date, modeling studies of cement-related materials have primarily focused on silicates and sulfates at various length scales, and few examples for aluminates are found. ${ }^{10,22,26}$ Prior reports on atomistic simulations of tricalcium aluminate $\left(\mathrm{Ca}_{3} \mathrm{Al}_{2} \mathrm{O}_{6}, \mathrm{C}_{3} \mathrm{~A}\right)$ at the scale of 1 to $100 \mathrm{~nm}$ are not known to us, and a force field was not available. This contribution aims at the introduction and thorough validation of an atomistic force field for tricalcium aluminate along with first applications to hydration and adsorption of organic modifiers. ${ }^{10,33-35}$

The outline of this paper is as follows. Key properties of tricalcium aluminate, the approach toward a force field, and parameters are described in section 2. Validation of the model and insight into structural, thermal, mechanical, and vibration properties is discussed in section 3 . In section 4 , surface properties, model representations of the hydration reaction, and interactions between cleaved surfaces before and after initial hydration are explored. In section 5 , the structure of organic thin films on the surfaces and their impact on agglomeration is analyzed. Conclusions are presented in section 6. Full computational details and additional information can be found in the ESI. $\dagger$

\section{Derivation of the force field}

\subsection{Key properties of tricalcium aluminate}

Tricalcium aluminate $\left(\mathrm{Ca}_{3} \mathrm{Al}_{2} \mathrm{O}_{6}, \mathrm{C}_{3} \mathrm{~A}\right)$ is the main aluminate phase in cement clinker $(5 \%-10 \%)$ and also used in dental root filling cements based on mineral trioxide aggregate (MTA). ${ }^{36}$ Pure tricalcium aluminate possesses a cubic crystal structure (Fig. 1). It is highly hygroscopic, forms poorly crystalline hydration products, and contributes to rapid setting of cement. $^{37-39}$ The exact concentration, or mass percentage, of tricalcium aluminate strongly influences cement setting properties and is important for the early development of compressive strength. ${ }^{40,41} \mathrm{C}_{3} \mathrm{~A}$ also forms a wide range of solid solutions, for example by replacement of $\mathrm{Al}^{3+}$ by $\mathrm{Fe}^{3+}$ and $\mathrm{Si}^{4+}$ in the range of $0-5 \%$, and substitution of $\mathrm{Ca}^{2+}$ by $\mathrm{Na}^{+}, \mathrm{K}^{+}$, and $\mathrm{Mg}^{2+}$ in the range $0-2 \%$. An impurity content over $3 \%$ can

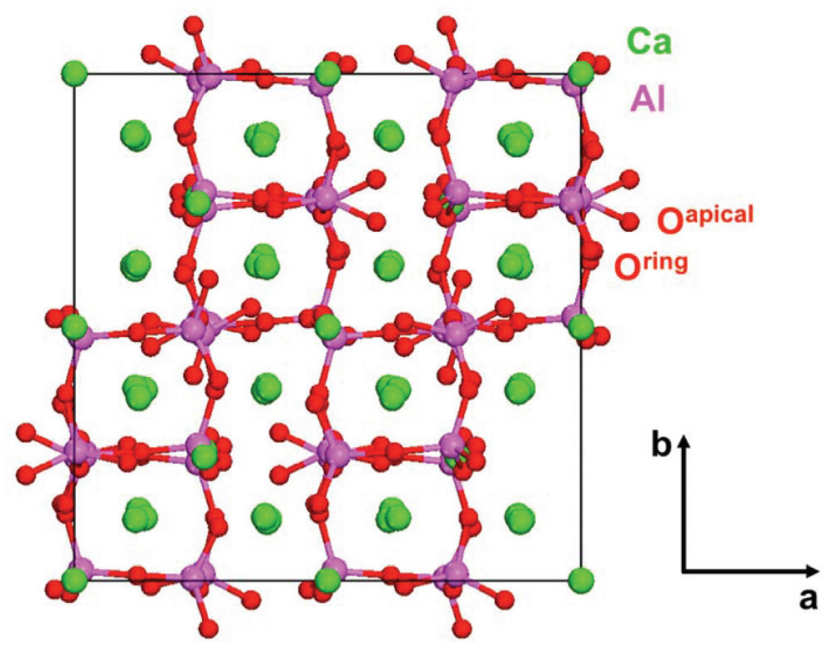

Fig. 1 Unit cell of tricalcium aluminate (cubic, space group $\mathrm{Pa} \overline{3}$, ref. 48). The lattice constant is $1.5263 \mathrm{~nm}$ and distinct atom types are labeled. Viewed from the $c$ axis onto the $a b$ plane.

modify the crystal structure from cubic to orthorhombic and several other polymorphs. ${ }^{37,42,43}$ In the derivation of the model, data for pure $\mathrm{C}_{3} \mathrm{~A}^{26,44-51}$ as well as $\mathrm{Ca}(\mathrm{OH})_{2}$ are taken as a reference. ${ }^{52}$ Customized local substitutions can be implemented as described earlier for clay minerals. ${ }^{20,53,54}$

\subsection{Approach toward an atomistic force field}

Molecular models of several cement minerals are available that reproduce structural and mechanical properties in good agreement with experiment. ${ }^{8,10,19,21-28}$ The largest portion of cement minerals is covered by the INTERFACE force field, ${ }^{8,10}$ which is also designed for compatibility with aqueous and organic interfaces and accurately reproduces interfacial properties in comparison to experiment. Such properties include cleavage energies, solid-water interface tensions, and binding energies of organic molecules to solid surfaces that are central for material performance. The uncertainties are in the low percent range in comparison to tens of percent in density functionals and deviations up to hundreds of percent in other force fields. Compounds in the INTERFACE force field are parameterized individually and typically reproduce structural properties with $<1 \%$ deviation from experiment, surface/interface properties with $<5 \%$ deviation from experiment, mechanical properties with $<10 \%$ deviation from experiment, and vibration spectra in good agreement with experiment.

The computation of accurate bulk and interfacial properties using such atomistic models depends mainly on three premises. (1) The balance of ionic versus covalent bonding needs to be accurately represented by atomic charges. ${ }^{10,20}$ This condition is fulfilled by assignments consistent with measured X-ray deformation electron densities, dipole moments, an Extended Born model, and known chemical reactivity for electronically and structurally similar compounds across the periodic table. (2) Computed surface properties are validated in comparison to available experimental data. ${ }^{10,54}$ This aspect 
is critical to avoid errors up to $500 \%$ as seen in earlier models and force fields derived from $a b$ initio methods. (3) Simplicity and broad applicability of the energy expression is desired. Simplicity of the energy expressions leads to fewer parameters, enables full interpretation of the parameters with a chemical and physical rationale, and eases extensions to related compounds as well as to chemical reactions. Broad applicability of the energy expression facilitates the usage of existing, thermodynamically consistent parameters for solvents and macromolecules in other force fields via standard combination rules to simulate inorganic-organic interfaces.

These premises of the INTERFACE approach enable the coverage of compounds across the periodic table (e.g. cement minerals, metals, biopolymers $)^{8,10,54,55}$ in high accuracy and full compatibility with harmonic force fields for biopolymers and organic molecules (CFF, PCFF,${ }^{56-58}$ COMPASS, ${ }^{59} \mathrm{CHARMM}^{60}$ AMBER, ${ }^{61}$ OPLS-AA, ${ }^{62}$ CVFF $\left.^{63}\right)$. The new parameters for tricalcium aluminate and partially hydrated phases contribute to this platform. ${ }^{10}$

\subsection{Choice of energy expressions}

Therefore, to facilitate broad applicability, multiple harmonic energy expressions were chosen. These include common force fields for organic molecules, biopolymers, solvents, and other inorganic phases, namely, CFF, PCFF, ${ }^{56-58}$ COMPASS (eqn (1)), ${ }^{59}$ CHARMM, ${ }^{60}$ AMBER, ${ }^{61,64}$ CVFF, $^{63}$ and OPLS-AA ${ }^{62}$ (eqn (2)):

$$
\begin{aligned}
E_{\text {pot }}= & \sum_{i j \text { bonded }} K_{r, i j}\left(r_{i j}-r_{0, i j}\right)^{2}+\sum_{i j k \text { bonded }} K_{\theta, i j k}\left(\theta_{i j k}-\theta_{0, i j k}\right)^{2} \\
& +\frac{1}{4 \pi \varepsilon_{0}} \sum_{i j \text { nonbonded }(1,3 \text { excl })} \frac{q_{i} q_{j}}{r_{i j}} \\
& +\sum_{i j \text { nonbonded }(1,3 \text { excl })} \varepsilon_{i j}\left[2\left(\frac{\sigma_{i j}}{r_{i j}}\right)^{9}-3\left(\frac{\sigma_{i j}}{r_{i j}}\right)^{6}\right]
\end{aligned}
$$

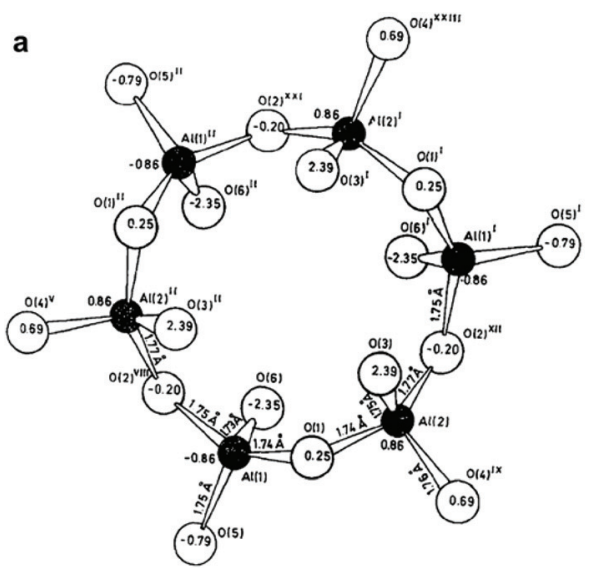

$$
\begin{aligned}
E_{\text {pot }}= & \sum_{i j \text { bonded }} K_{r, i j}\left(r_{i j}-r_{0, i j}\right)^{2}+\sum_{i j k \text { bonded }} K_{\theta, i j k}\left(\theta_{i j k}-\theta_{0, i j k}\right)^{2} \\
& +\frac{1}{4 \pi \varepsilon_{0}} \sum_{i j \text { nonbonded }(1,3 \text { excl })} \frac{q_{i} q_{j}}{r_{i j}} \\
& +\sum_{i j \text { nonbonded }(1,3 \text { excl })} \varepsilon_{i j}\left[\left(\frac{\sigma_{i j}}{r_{i j}}\right)^{12}-2\left(\frac{\sigma_{i j}}{r_{i j}}\right)^{6}\right]
\end{aligned}
$$

The energy expressions contain harmonic bond stretching and angle bending terms for bonded interactions, as well as Coulomb and Lennard-Jones terms for nonbonded interactions (electrostatic and van der Waals contributions). This combination offers a suitable description of molecular features in minerals, as previously shown, ${ }^{8,10,53,54}$ and the application of standard combination rules enables the simulation of interfaces with solvents, organic, and inorganic molecules in high accuracy. $^{10}$

\subsection{Derivation and interpretation of individual parameters}

The parameterization procedure followed the INTERFACE approach that involves (1) retrieval of the crystal structure of tricalcium aluminate from X-ray data, (2) definition of atom types, (3) assignment of atomic charges, (4) assignment of initial bonded and Lennard-Jones parameters, (5) computational tests of density and geometry followed by refinements, (6) computational tests of surface properties followed by refinements, and (7) secondary validation (vibration, thermal, and mechanical properties). ${ }^{10}$

$\mathrm{X}$-ray data reveal that pure tricalcium aluminate consists of $\mathrm{Al}_{6} \mathrm{O}_{18}$ rings and calcium ions with a net stoichiometry $\mathrm{Ca}_{3} \mathrm{Al}_{2} \mathrm{O}_{6}$ (Fig. 1 and 2). ${ }^{48}$ Four chemically distinct atom types can be identified similar to the concept of chemical equivalence in NMR spectroscopy. These include calcium, aluminum, apical oxygen, and ring oxygen. This level of differentiation proved to be sufficient for a well-performing force field. Four further atom types are generated upon partial hydration

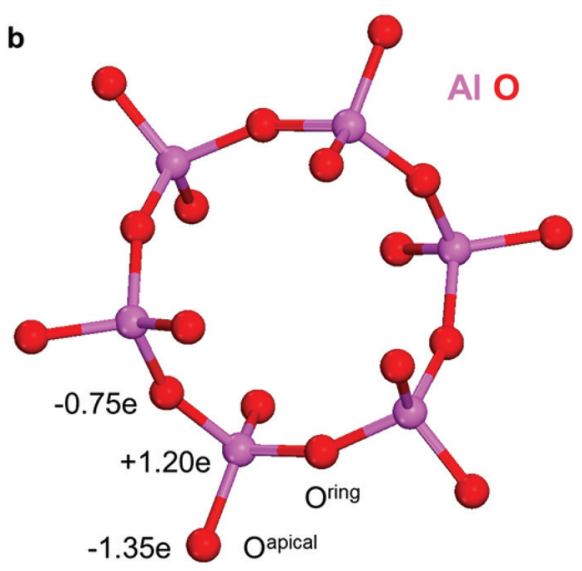

Fig. 2 The structure of aluminate rings in tricalcium aluminate according to $\mathrm{X}$-ray data and computation with the force field. (a) $\mathrm{Al}_{6} \mathrm{O}_{18}$ rings consist of six $\mathrm{AlO}_{4}$ tetrahedra connected by bridging $\mathrm{O}$ atoms according to experiment (from ref. 48). Ring atoms exhibit minor variations in bond length, and bond angles deviate somewhat from ideal tetrahedral values due to a puckered structure. (b) Equilibrium geometry of the aluminate ring according to MD simulation in the NPT ensemble. A close match to experiment can be seen and atomic charges in the force field are indicated. 
Table 1 Force field parameters for tricalcium aluminate and initially hydrated surfaces. Different energy expressions such as CFF/PCFF/COMPASS, CHARMM, CVFF, AMBER, OPLS-AA have some parameters in common $\left(q_{i}, K_{r, j}, K_{\theta, i j k}\right)$ while others are specific due to minor differences in functional form $\left(\sigma_{i i}, \varepsilon_{i i}, r_{0, i j}, \theta_{0, i j k}\right)$

\begin{tabular}{|c|c|c|c|c|}
\hline \multirow[b]{2}{*}{ I. Nonbond } & \multirow[b]{2}{*}{$q_{i}(e)$} & \multicolumn{3}{|l|}{$\sigma_{i i}(\mathrm{pm}), \varepsilon_{i i}\left(\mathrm{kcal} \mathrm{mol}^{-1}\right)$} \\
\hline & & CFF, PCFF, COMPASS ${ }^{a}$ & CHARMM, $\mathrm{CVFF}^{b, c}$ & AMBER, OPLS-AA ${ }^{b, c}$ \\
\hline $\mathrm{Ca}$ & +1.50 & $355,0.24$ & $330,0.15$ & $330,0.15$ \\
\hline $\mathrm{Al}$ & +1.20 & $480,0.50$ & $460,0.50$ & $460,0.50$ \\
\hline $\mathrm{O}^{\text {ring }}$ & -0.75 & $362,0.06$ & $350,0.08$ & $342,0.08$ \\
\hline $\mathrm{O}^{\text {apical }}$ & -1.35 & $352,0.06$ & $340,0.08$ & $332,0.08$ \\
\hline $\mathrm{O}$ in $\mathrm{AlOH}$ & -0.90 & $352,0.06$ & $340,0.08$ & $332,0.08$ \\
\hline $\mathrm{H}$ in $\mathrm{AlOH}$ & +0.30 & $109.8,0.013$ & $0,0^{d}$ & $0,0^{d}$ \\
\hline $\mathrm{O}$ in $\mathrm{OH}^{-}$ & -1.00 & $360,0.12$ & $347,0.12$ & $347,0.12$ \\
\hline $\mathrm{H}$ in $\mathrm{OH}^{-}$ & +0.25 & $109.8,0.013$ & $0,0^{d}$ & $0,0^{d}$ \\
\hline \multicolumn{2}{|l|}{ II. Bonds } & \multicolumn{2}{|l|}{$r_{0, i j}(\mathrm{pm})$} & $K_{r, i j}\left[\mathrm{kcal}\left(\mathrm{mol} \AA^{2}\right)^{-1}\right]$ \\
\hline \multirow{3}{*}{\multicolumn{2}{|c|}{$\begin{array}{l}\mathrm{Al}-\mathrm{O}^{\text {ring }} \\
\mathrm{Al}-\mathrm{O}^{\text {apical }} \\
\mathrm{O}-\mathrm{H}\left(\text { in } \mathrm{AlOH} \text { and } \mathrm{OH}^{-}\right)\end{array}$}} & \multicolumn{2}{|c|}{198 (AMBER: 194; OPLS-AA: 181.5$)^{c}$} & 180 \\
\hline & & \multicolumn{2}{|c|}{181 (OPLS-AA: 177.5$)^{c}$} & 180 \\
\hline & & \multicolumn{2}{|c|}{92.9} & 495 \\
\hline \multicolumn{2}{|l|}{ III. Angles } & \multicolumn{2}{|l|}{$\theta_{0, j j k}\left({ }^{\circ}\right)$} & $K_{\theta, j j k}\left[\mathrm{kcal}\left(\mathrm{mol} \mathrm{rad}^{2}\right)^{-1}\right]$ \\
\hline \multicolumn{2}{|l|}{$\mathrm{O}^{\text {ring }}-\mathrm{Al}-\mathrm{O}^{\text {ring }}$} & \multicolumn{2}{|c|}{111.5} & 110 \\
\hline & \multicolumn{2}{|c|}{156.7 (OPLS-AA: 152.0$)^{c}$} & 110 \\
\hline \multicolumn{2}{|l|}{$\mathrm{O}^{\text {ring }}-\mathrm{Al}-\mathrm{O}^{\text {apical }}$} & \multicolumn{2}{|c|}{105.0} & 110 \\
\hline \multicolumn{2}{|l|}{$\mathrm{O}^{\text {apical }}-\mathrm{Al}-\mathrm{O}^{\text {apical }}$} & \multicolumn{2}{|l|}{121.0} & 110 \\
\hline \multicolumn{2}{|l|}{$\mathrm{H}-\mathrm{O}^{\text {apical }}-\mathrm{Al}($ in $\mathrm{AlOH})$} & \multicolumn{2}{|l|}{115.0} & 40 \\
\hline
\end{tabular}

(Table 1), including oxygen and hydrogen in aluminol groups as well as oxygen and hydrogen in hydroxide ions. These atom types share similarities with $\mathrm{AlOH}$ groups in ettringite and with $\mathrm{OH}^{-}$ions in calcium hydroxide, respectively. ${ }^{8,10}$

Atomic charges $q_{i}$ were then assigned on the basis of multiple experimental properties according to Heinz et al. (Fig. 2 and Table 1). ${ }^{20}$ Key data are atomic charges derived from X-ray deformation densities for closely related compounds, dipole moments, and an extended Born model. The extended Born model relies on available atomization energies, ionization potentials, and coordination numbers, as well as comparisons to structurally and electronically similar compounds across the periodic table. Melting points, acid-base reactivity, affinity to hydrolysis, and $a b$ initio charges were also taken into account as previously described, aiding in convergence testing of the derived atomic charges. ${ }^{10,20}$ The resulting aluminum charge in the $\mathrm{Al}_{6} \mathrm{O}_{18}$ rings in tetrahedral oxygen coordination is $+1.2 \pm$ $0.1 e$, slightly lower than $+1.45 e$ in octahedral oxygen coordination as found in diaspore and in pyrophyllite. ${ }^{10,20,54}$ Accordingly, Al-O bonds in tetrahedral oxygen coordination have more covalent character and are slightly shorter than in octahedral oxygen coordination. ${ }^{48}$ Calcium is embedded in coordination environments similar to tricalcium silicate and hydroxyapatite with a charge of $+1.5 \pm 0.1 e$, resulting in partly covalent bonding that is common in further calcium salts. ${ }^{10,20}$ The corresponding negative charges on oxygen were distributed over ring and apical sites under the condition of overall charge neutrality. A higher negative charge is concentrated on the monovalent apical oxygen atoms $(-1.35 e)$ and a lower negative charge on the divalent ring oxygen atoms $(-0.75 e)$, in accordance with less covalent character and closer contact of apical oxygen atoms with calcium ions (Fig. 2 and Table 1). ${ }^{48}$ The exact balance was confirmed through best structural fit in the simulation. Upon initial reaction with water, apical oxygen atoms form aluminol groups and hydroxide ions. Aluminol hydrogen is less acidic than silanol hydrogen $(+0.40 e)$; therefore it carries a charge of $+0.30 e$ and leads to a charge of $-0.90 e$ on aluminol oxygen. ${ }^{20,54}$ Hydroxide ions are approximated by charges of $-1.0 e$ and $+0.25 e$ for $\mathrm{O}$ and $\mathrm{H}$ for $\mathrm{a}$ total charge of $-0.75 e$.

Bonded terms were assigned between neighbor atoms that carry less than or equal to half the formal charge and have a short distance, corresponding to a predominantly covalent bond (Table 1). ${ }^{10}$ In addition, all atoms participate in nonbond interactions. Accordingly, only atoms in the $\mathrm{Al}_{6} \mathrm{O}_{18}$ rings possess bonded terms and the initial bonded parameters $r_{0, i j}$ and $\theta_{0, i j k}$ were chosen from the X-ray structure. ${ }^{48}$ Final parameters $r_{0, i j}$ for the $\mathrm{Al}-\mathrm{O}$ bonds were obtained by refinement so that the average bond length of $175 \mathrm{pm}$ in X-ray data is reproduced in NPT molecular dynamics simulation (Table 1). The precise values $r_{0, i j}$ are up to $13 \%$ higher to offset strongly attractive Coulomb interactions that depend on 
scaling conventions of nonbond interactions between 1,4 bonded atoms. Accordingly, $r_{0, i j}$ is $198 \mathrm{pm}$ (ring) and $181 \mathrm{pm}$ (apical) in PCFF and CHARMM with 100\% inclusion of 1,4 Coulomb forces, but only $181.5 \mathrm{pm}$ and $177.5 \mathrm{pm}$ in OPLS-AA with $50 \%$ inclusion of 1,4 Coulomb forces. Final parameters $\theta_{0, i j k}$ for the bond angles were obtained upon refinement in NPT molecular dynamics simulation so that average bond angles from X-ray data are reproduced. Modifications were $<3 \%$. Vibration constants $K_{r, i j}$ and $K_{\theta, i j k}$ were initially estimated from clay minerals and refined to reasonably reproduce Infrared (IR) and Raman spectra during molecular dynamics. ${ }^{45-47,49,51,54}$ The resulting bond stretching constants $K_{r, i j}$ for $\mathrm{Al}-\mathrm{O}$ bonds are uniformly $180 \mathrm{kcal}\left(\mathrm{mol} \AA^{2}\right)^{-1}$ and angle bending constants $K_{\theta, i j k}$ for Al-O-Al and O-Al-O angles are uniformly $110 \mathrm{kcal}\left(\mathrm{mol} \mathrm{rad}^{2}\right)^{-1}$.

Initial Lennard-Jones (LJ) parameters $\sigma_{i i}$ and $\varepsilon_{i i}$ for each atom type were assigned on the basis of van der Waals radius, polarizability, and coordination environment (Table 1) (see ref. 10, 54 and 65). The LJ parameters were subsequently refined for best reproduction of lattice constants and structural match with X-ray data for each energy expression, including extensive tests of the well depths $\varepsilon_{i i}$ and nonbond diameters $\sigma_{i i}$. For a highly polar mineral such as $\mathrm{C}_{3} \mathrm{~A}$, larger well depths $\varepsilon_{i i}$ increase interatomic repulsion by increasing the slope of the repulsive portion of the LJ potential and have a similar effect as a larger nonbond diameter $\sigma_{i i}$ on computed cell parameters. Secondary validation of surface, thermal, and mechanical properties provided instantly a good match with available experimental data. This agreement is a consequence of the chemically informed assignment and interpretation of all parameters in the context of verifiable experimental properties, and demonstrates thermodynamic consistency. Finally, the influence of all parameters on key properties was individually tested in more than 100 further test calculations and minor adjustments were made.

The parameters using a 9-6 LJ potential (eqn (1)) were then transcribed to energy expressions with a 12-6 LJ potential (eqn (2)) using known trends ${ }^{8,54,55}$ and fine-tuned to reproduce lattice constant and structural parameters. Some additional differentiation in LJ parameters $\sigma_{i i}, \varepsilon_{i i}$, equilibrium bond lengths $r_{0, i j}$, and angles $\theta_{0, i j k}$ was made due to specific scaling conventions of nonbond interactions between 1,4 bonded atoms and combination rules. Finally, the influence of all parameters on key properties was individually tested for each energy expression in over 500 further test calculations and minor adjustments were made. All energy expressions (eqn (1) and (2)) compute essentially the same properties. The parameters for $\mathrm{C}_{3} \mathrm{~A}$ are consistent with those for other compounds in the INTERFACE force field, including layered silicates, silica, and tricalcium silicate that underwent equally rigorous evaluation. . $^{8,10,54}$

The assignment and refinement of force field parameters on the basis of chemical knowledge is a great advantage over "black-box" assignments from ab initio simulations, which typically lead to poor results and lack rational explanation. Chemical accuracy in atomic charges was achieved for pure and hydrated phases, as well as full understanding of all parameters and relative simplicity of the force field, which is paramount to examine chemical reactions. Therefore, the force field can be seen as a "molecular code" to understand nanoscale properties of tricalcium aluminate and its initial hydrates.

\section{Validation of structural, thermal, mechanical, and vibration properties}

The force field computes structural, thermal, mechanical, and vibration properties in very good agreement with experiment, which helps establish the reliability of the force field and explains molecular details. Surface properties will be specifically discussed in section 4 .

\subsection{Structural and thermal properties}

NPT molecular dynamics simulation of tricalcium aluminate under standard conditions reproduces bond lengths and angles of the $\mathrm{Al}_{6} \mathrm{O}_{18}$ rings with less than $1 \%$ average deviation from X-ray data (Fig. 2, Table 2). The root mean square (rms) deviation in atomic positions from X-ray measurements is between 0.03 and $0.05 \AA$. Computed unit cell parameters and density agree better than $0.5 \%$ with X-ray data for all energy expressions (Table 3).

The crystal structure is also stable in NPT simulations up to $1500{ }^{\circ} \mathrm{C}$. Increasing fluctuations in atomic positions are noted towards the melting and decomposition point at $1542{ }^{\circ} \mathrm{C}$ in experiment. The computed temperature dependence of the lattice parameter indicates near-linear thermal expansion between $300 \mathrm{~K}$ and $800 \mathrm{~K}$ (Fig. 3), and the linear thermal expansion coefficient averages $11.5 \pm 1.5 \times 10^{-6} \mathrm{~K}^{-1}$ in agreement with measurements ranging from $10 \times 10^{-6}$ to

Table 2 Comparison of average bond lengths and angles of the puckered $\mathrm{Al}_{6} \mathrm{O}_{18}$ ring according to X-ray data (ref. 48) and in NPT simulation at 298 K (PCFF)

\begin{tabular}{|c|c|c|c|c|c|}
\hline \multicolumn{3}{|c|}{ Bond lengths (pm) } & \multicolumn{3}{|l|}{ Bond angles $\left(^{\circ}\right)$} \\
\hline $\mathrm{Al}-\mathrm{O}^{\text {apical }}$ & $175.0 \pm 2.0$ & $174.5 \pm 2.0$ & $\begin{array}{l}\mathrm{Al}-\mathrm{O}^{\text {ring }}-\mathrm{Al} \\
\mathrm{O}^{\text {ring }}-\mathrm{Al}-\mathrm{O}^{\text {apical }} \\
\mathrm{O}^{\text {apical }}-\mathrm{Al}-\mathrm{O}^{\text {apical }}\end{array}$ & $\begin{array}{l}152.3 \pm 2.9 \\
105.4 \pm 3.7 \\
123.1 \pm 1.3\end{array}$ & $\begin{array}{l}151.0 \pm 4.0 \\
105.5 \pm 4.5 \\
123.3 \pm 3.0\end{array}$ \\
\hline
\end{tabular}


Table 3 Cell parameters of tricalcium aluminate according to X-ray data (ref. 48) and molecular dynamics simulation with different force fields in the NPT ensemble under standard temperature and pressure

\begin{tabular}{|c|c|c|c|c|c|c|c|c|}
\hline Method & Cell dim. & $a(\mathrm{~nm})$ & $b(\mathrm{~nm})$ & $c(\mathrm{~nm})$ & $\alpha\left(^{\circ}\right)$ & $\beta\left(^{\circ}\right)$ & $\gamma\left({ }^{\circ}\right)$ & $\rho\left(\mathrm{kg} \mathrm{m}^{-3}\right)$ \\
\hline Experiment & $1 \times 1 \times 1$ & 1.5263 & 1.5263 & 1.5263 & 90 & 90 & 90 & 3027 (2) \\
\hline PCFF, CFF, COMPASS & $1 \times 1 \times 1$ & 1.5265 & 1.5260 & 1.5260 & 90 & 90 & 90 & 3028 \\
\hline CVFF & $1 \times 1 \times 1$ & 1.5240 & 1.5240 & 1.5240 & 90 & 90 & 90 & 3040 \\
\hline AMBER & $1 \times 1 \times 1$ & 1.5267 & 1.5267 & 1.5267 & 90 & 90 & 90 & 3025 \\
\hline OPLS-AA & $1 \times 1 \times 1$ & 1.5258 & 1.5258 & 1.5258 & 90 & 90 & 90 & 3030 \\
\hline
\end{tabular}

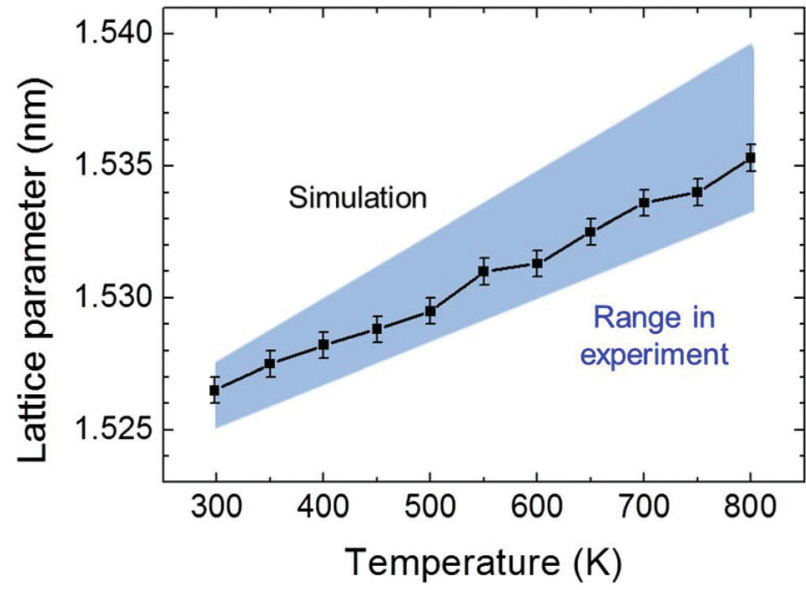

Fig. 3 Thermal expansion of the lattice parameter $a$ of $C_{3} A$ under standard pressure in NPT molecular dynamics simulation and in experimental measurements (shaded area according to ref. 44).

$15 \times 10^{-6} \mathrm{~K}^{-1}{ }^{44}$ The small number of force field types and parameters thus reproduces structural and thermal properties very well.

\subsection{Mechanical properties}

Tricalcium aluminate is known to play an important role in the early development of compressive strength of cement through the various hydrates that form in the reaction with water. ${ }^{22,26,50}$ Besides, also the mechanical properties of pure $\mathrm{C}_{3} \mathrm{~A}$ have been studied using nanoindentation, high-pressure X-ray diffraction, and resonance frequency methods, ${ }^{26,50}$ as well as by density functional theory (Table 4). ${ }^{22,26}$ Results with the force field fall fully within the experimental uncertainty and can be applied to length and time scales a million times larger than with ab initio methods (Fig. 4 and Table 4).

Table 4 Experimental and computed elastic properties of tricalcium aluminate, using molecular dynamics simulation in the NPT ensemble

\begin{tabular}{llc}
\hline Elastic properties & Experiment & Computed (PCFF) \\
\hline Bulk modulus $(K), \mathrm{GPa}$ & $106 \pm 8^{a}\left(\mathrm{DFT}: 102.9^{b}\right)$ & $98 \pm 3$ \\
Young's modulus $(E), \mathrm{GPa}$ & $135 \pm 7^{a}, 145 \pm 10^{c}$ & $134 \pm 5$ \\
Poisson ratio & $0.285 \pm 0.01^{a}$ & $0.29 \pm 0.03$
\end{tabular}

${ }^{a}$ Ref. 26. ${ }^{b}$ Ref. 22. ${ }^{c}$ Ref. 50. The Young's modulus was identified as $(145 \pm 10) \mathrm{GPa}$ by nanoindentation and up to higher values of $(160 \pm$ 10) GPa by resonance frequency techniques.
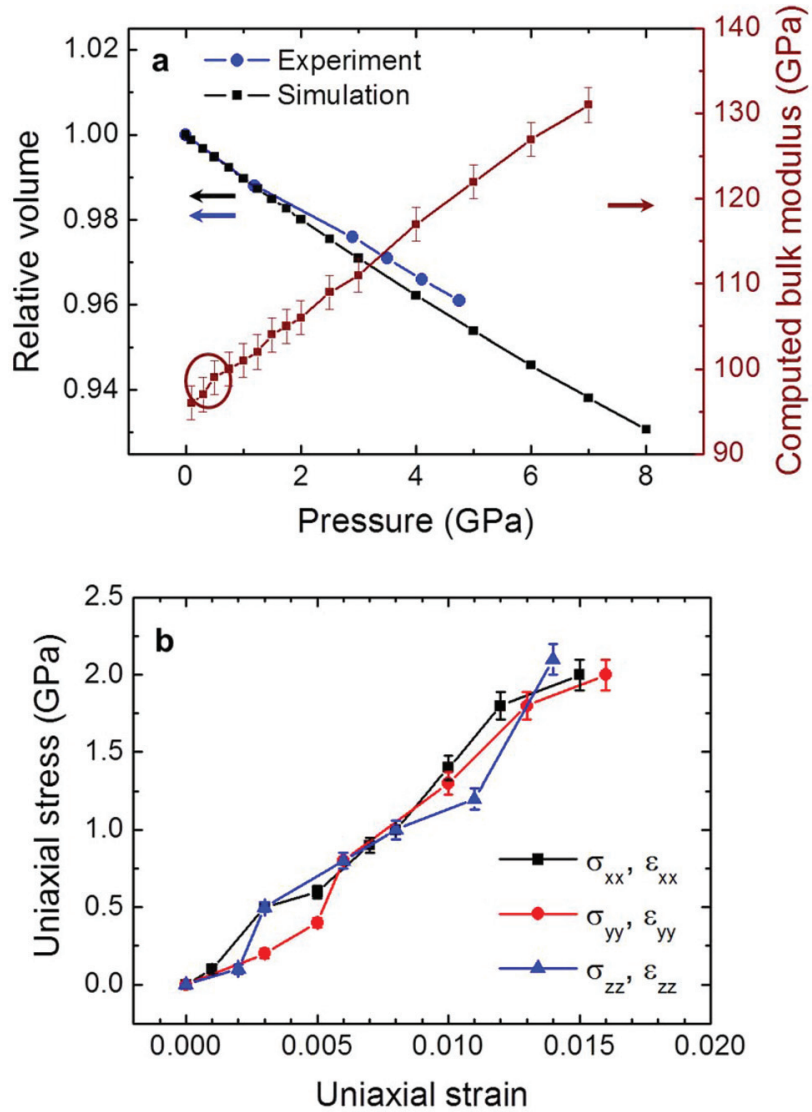

Fig. 4 Isothermal compression and stress-strain curves of tricalcium aluminate along the principal directions in NPT molecular dynamics simulation at $298 \mathrm{~K}$. (a) The volume decreases approximately linear as a function of pressure, with a softening slope, in agreement with experimental compression data (from ref. 26). The bulk modulus increases approximately linear under higher pressure. (b) Computed stress-strain curves in $x, y$, and $z$ direction. The average slope at low strain equals Young's modulus.

Computed isotropic compression and stress-strain curves proceed approximately linear as a function of stress. The volume decrement upon compression slightly decreases under higher pressure, leading to an increase in bulk modulus at higher pressure (Fig. 4a). These observations agree with experimental compression data, including a bulk modulus $K$ near $100 \mathrm{GPa}$ at low stress $(<1 \mathrm{GPa})$ and a higher bulk modulus over $120 \mathrm{GPa}$ at high stress $(>4 \mathrm{GPa}) .{ }^{26}$ The trend is also consistent with a decreasing slope of the experimental compression curve 
and with resonance frequency measurements of Young's moduli $E$ up to $160 \mathrm{GPa},{ }^{50}$ which correspond to Bulk moduli up to $127 \mathrm{GPa}$ according to the relationship $K=E /[3(1-2 \nu)]$ for isotropic elastic solids (Table 4). ${ }^{66}$ Computed uniaxial stress-strain curves along the three principal axes $x, y$, and $z$ converge to the same Young's modulus $E$ of $134 \pm 5 \mathrm{GPa}$ within small deviations (Fig. 4b). The Poisson ratio $\nu$ was identified as $\sim 0.29$. Measurements indicate Young's moduli in the range 135 to $145 \mathrm{GPa}$ at low stress. ${ }^{26,50}$

The capability of quantitative predictions of mechanical properties can also be applied to heterogeneous mineral structures in dry and hydrated cements using existing parameters for other cement phases. ${ }^{10}$

\subsection{Vibration properties}

$\mathrm{IR}^{51}$ and Raman spectra ${ }^{38}$ of tricalcium aluminate are also approximated in molecular dynamics simulation (Fig. 5). Absorption bands in the frequency range of 920 to $700 \mathrm{~cm}^{-1}$ correspond to stretching vibrations of $\mathrm{Al}-\mathrm{O}$ bonds in the aluminate rings ${ }^{45-47,49,51}$ and a very good fit within $20 \mathrm{~cm}^{-1}$ between model and experiment is seen. Intensities are only approximately reproducible in a non-quantum mechanical

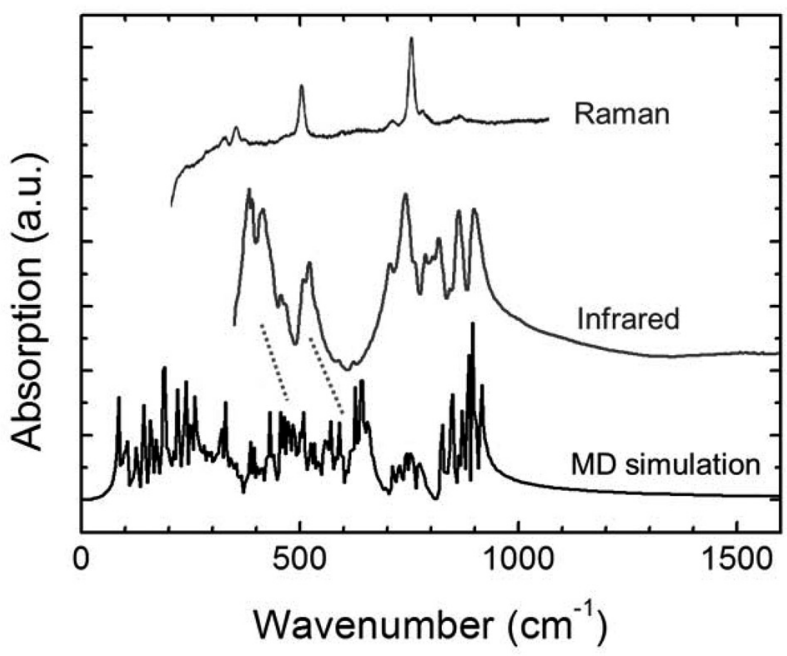

Fig. 5 Vibration spectra of tricalcium aluminate in experiment and in molecular dynamics simulation (Raman data from ref. 38 and IR data from ref. 51). Regions for angle bending (300-550 $\mathrm{cm}^{-1}$ ) and bond stretching $\left(700-920 \mathrm{~cm}^{-1}\right.$ ) can be seen. A slight mismatch in angle bending vibrations can be seen. model. ${ }^{54}$ The frequency range of 550 to $300 \mathrm{~cm}^{-1}$ corresponds to bending vibrations of $\mathrm{Al}-\mathrm{O}-\mathrm{Al}$ and $\mathrm{O}-\mathrm{Al}-\mathrm{O}$ angles. These bands are shifted by approximately $100 \mathrm{~cm}^{-1}$ upwards in molecular dynamics simulation to support structural stability and accuracy of bond angles up to high temperature (see section $\mathrm{S} 1.5$ in the ESI $\dagger$ for details).

Bands in the range of 700 to $500 \mathrm{~cm}^{-1}$ were also observed in measurements although they are likely associated with condensed $\mathrm{AlO}_{6}$ octahedra upon progressive hydration. ${ }^{45-47,49,51,67}$ Such structural elements are not present in this model although they can be introduced using structural features in ettringite or monosulphate. ${ }^{10}$

\subsection{Performance of different energy expressions}

The performance of the force field does not significantly depend on the energy expression, as shown by benchmarks for structural properties, surface properties, and mechanical properties (Table 5). Structural properties exhibit only minor variations; only the force fields AMBER and OPLS exhibit a slightly wider distribution of the $\mathrm{Ca}^{2+}$ ions inside the channel-like arrangement of aluminate rings (Fig. 1). 12-6 LJ parameters are slightly more repulsive than 9-6 LJ parameters so that cleavage energies are $5-10 \%$ higher and the bulk modulus is approximately $107 \mathrm{GPa}$ instead of $98 \mathrm{GPa}$, even closer to experiment (Table 4). These differences are small and reflect performance limits due the mathematical form of the energy expressions, including differences in the type of LennardJones potential, combination rules, and scaling of nonbond interactions between 1,4 bonded atoms.

\section{Cleavage, hydration, and agglomeration of tricalcium aluminate surfaces}

Particle cleavage plays a major role in processing of minerals, rocks, ores, as well as composite materials. ${ }^{7,8,68-71}$ The associated energies of cleavage and agglomeration characterize the individual surfaces and can be challenging to measure for specific $(h k l$ ) facets, especially when accompanied by chemical reactions. ${ }^{52,68,72}$ Molecular models can monitor such processes in atomic resolution to gain mechanistic insight, elucidate experimentally unavailable data, and provide further validation.

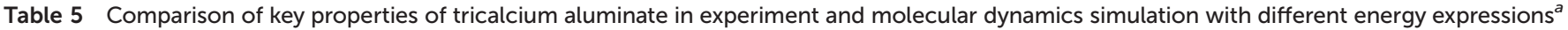

\begin{tabular}{|c|c|c|c|c|c|c|}
\hline Property & Expt & PCFF & CHARMM & CVFF & AMBER & OPLS-AA \\
\hline Lattice parameter $a(\mathrm{~nm})$ & $1.5263^{b}$ & 1.5265 & 1.5280 & 1.5240 & 1.5267 & 1.5258 \\
\hline $\mathrm{Al}-\mathrm{O}^{\text {ring }}$ bond length $(\mathrm{pm})$ & $175.5^{b}$ & 174.5 & 174.0 & 173.5 & 176.0 & 175.5 \\
\hline $\mathrm{Al}-\mathrm{O}^{\text {apical }}$ bond length (pm) & $175.0^{b}$ & 174.5 & 172.5 & 172.0 & 174.5 & 174.5 \\
\hline Cleavage energy $\left(\mathrm{mJ} \mathrm{m}^{-2}\right)$ & $1250 \pm 150( \pm 12 \%)^{c}$ & $1260( \pm 0 \%)$ & $1325(+5.2 \%)$ & $1321(+4.1 \%)$ & $1341(+6.4 \%)$ & $1380(+9.5 \%)$ \\
\hline Bulk modulus (GPa) at $0-1 \mathrm{GPa}$ & $106 \pm 8^{d}$ & $98 \pm 3$ & $107 \pm 3$ & $108 \pm 3$ & $107 \pm 3$ & $108 \pm 3$ \\
\hline
\end{tabular}

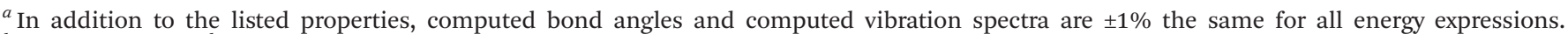

${ }^{b}$ Ref. 48. ${ }^{c}$ Ref. 52. ${ }^{d}$ Ref. 26.
} 
a

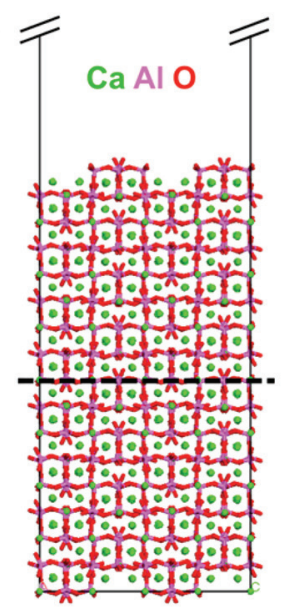

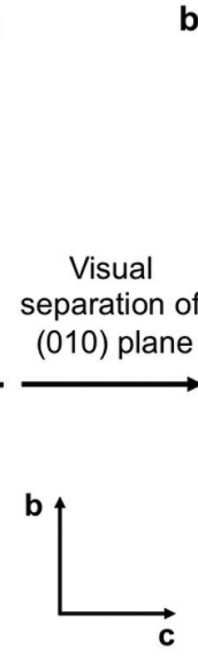

b

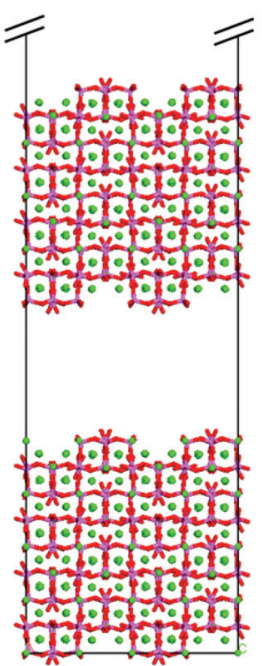

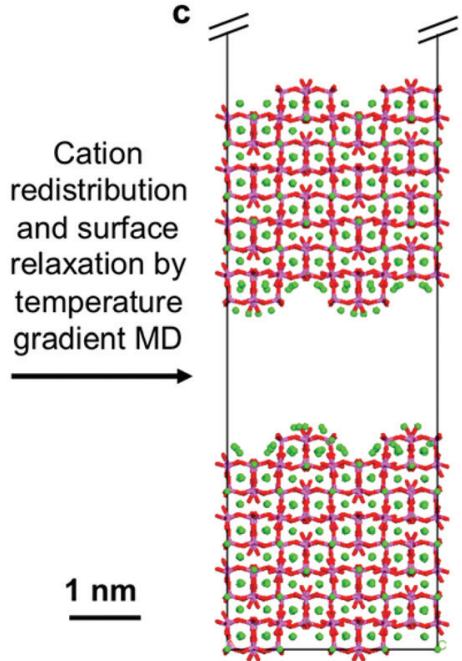

Fig. 6 Generation of model surfaces of lowest energy upon cleavage for the example of the (010) cleavage plane. (a) An electroneutral slab of $C_{3} A$. (b) Initial separation of (010) surfaces by at least $2 \mathrm{~nm}$ with an arbitrary distribution of surface cations. (c) Equilibrium surfaces with electroneutral distribution of cations after temperature gradient molecular dynamics (ref. 72).

Table 6 Computed equilibrium cleavage energy and agglomeration energy of $\mathrm{C}_{3} \mathrm{~A}$. The agglomeration energy depends on temperature, initial hydration $(\mathrm{HO}, \mathrm{H} 1)$ and surface displacement after cleavage (D0, D1). ${ }^{a}$ The $(100)$ cleavage plane is of lowest energy and equivalent to several other planes (see text)

\begin{tabular}{|c|c|c|}
\hline Cleavage plane & Temperature (K) & Cleavage energy $\left(\mathrm{mJ} \mathrm{m}^{-2}\right)$ \\
\hline$\left(\begin{array}{lll}1 & 0 & 0\end{array}\right)$ & 298 & $1260 \pm 50$ \\
\hline$\left(\begin{array}{lll}1 & 0 & 0\end{array}\right)$ & 363 & $1210 \pm 50$ \\
\hline Expt: $\mathrm{Ca}(\mathrm{OH})_{2}, \mathrm{CaO}$ & 298 & $1180 \pm 100,1310 \pm 200^{b}$ \\
\hline Agglomeration plane $^{a}$ & Temperature (K) & Agglomeration energy $\left(\mathrm{mJ} \mathrm{m}^{-2}\right)$ \\
\hline$\left(\begin{array}{lll}1 & 0 & 0\end{array}\right), \mathrm{H} 0, \mathrm{D} 0$ & 298 & $860 \pm 40$ \\
\hline$\left(\begin{array}{lll}1 & 0 & 0\end{array}\right), \mathrm{H} 0, \mathrm{D} 0$ & 363 & $720 \pm 45$ \\
\hline$\left(\begin{array}{lll}1 & 0 & 0\end{array}\right), \mathrm{H} 0, \mathrm{D} 1$ & 363 & $300 \pm 50$ \\
\hline$\left(\begin{array}{lll}1 & 0 & 0\end{array}\right), \mathrm{H} 1, \mathrm{D} 0$ & 298 & $520 \pm 30$ \\
\hline$\left(\begin{array}{lll}1 & 0 & 0\end{array}\right), \mathrm{H} 1, \mathrm{D} 0$ & 363 & $500 \pm 40$ \\
\hline$\left(\begin{array}{lll}1 & 0 & 0\end{array}\right), \mathrm{H} 1, \mathrm{D} 1$ & 363 & $250 \pm 30$ \\
\hline
\end{tabular}

a "H0" indicates no hydration and "H1" initial hydration after cleavage. "D0" indicates no surface displacement and "D1" a specified surface displacement after cleavage (Fig. 9). Data for another displacement D1' range between D0 and D1 (Fig. 9). ${ }^{b}$ Ref. 52.

\subsection{Cleavage energy}

Many possible cleavage planes of tricalcium aluminate, such as (100), (010), (001), (200), (020), and (002) are identical due to cubic crystal symmetry (Fig. 6). These cleavage planes are of lower energy than others, such as (111), due to the orientation of calcium ions and aluminate rings in "channels" along the coordinate axes. The cleavage energy of (100) planes upon equilibrium cleavage at $25{ }^{\circ} \mathrm{C}$ was computed as $1260 \pm$ $50 \mathrm{~mJ} \mathrm{~m}^{-2}$ (Table 6). An increase in temperature to $90^{\circ} \mathrm{C}$, typically employed for particle grinding, lowered the cohesive energy by approximately $5 \%$ to $1210 \pm 50 \mathrm{~mJ} \mathrm{~m}^{-2}$. Experimentally determined cleavage energies for $\mathrm{Ca}_{3} \mathrm{Al}_{2} \mathrm{O}_{6}$ are not available, however, the computational results are close to reported measurements of 1100 to $1400 \mathrm{~mJ} \mathrm{~m}^{-2}$ for similar minerals such as $\mathrm{Ca}(\mathrm{OH})_{2}$ and $\mathrm{CaO}$ that are of comparable polarity. ${ }^{52}$
In the calculation of the cleavage energy, it was assumed that the two models surfaces possess equal amounts of $\mathrm{Ca}^{2+}$ cations in a low-energy distribution after cleavage, identified by temperature-gradient protocols in the simulation (Fig. 6). ${ }^{8,68,72}$ In this manner, each surface remains electrically neutral and exhibits minimal local electric fields. Higher, distancedependent cleavage energies were also observed by rapid, nonequilibrium cleavage.

\subsection{Initial hydration of the $\mathrm{C}_{3} \mathrm{~A}$ surface}

Water reacts instantly with tricalcium aluminate. ${ }^{37}$ Hydration likely begins already during grinding of cement clinker at $90{ }^{\circ} \mathrm{C}$ due to residual humidity and dehydration of gypsum additives. Initial contact with water causes protonation of single bonded oxygen atoms on aluminate rings and leads to the formation of calcium hydroxide (Scheme 1). 


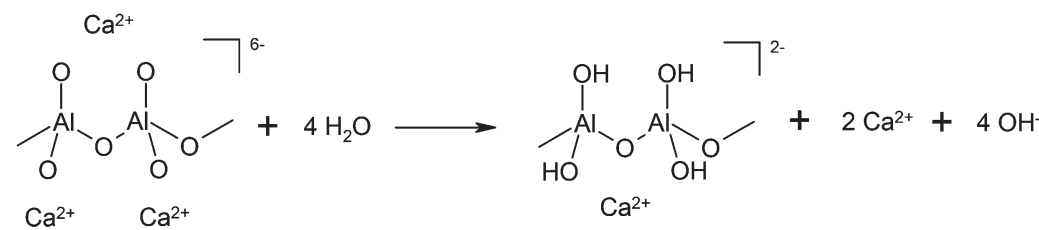

Scheme 1 Initial hydration of an aluminate ring fragment.

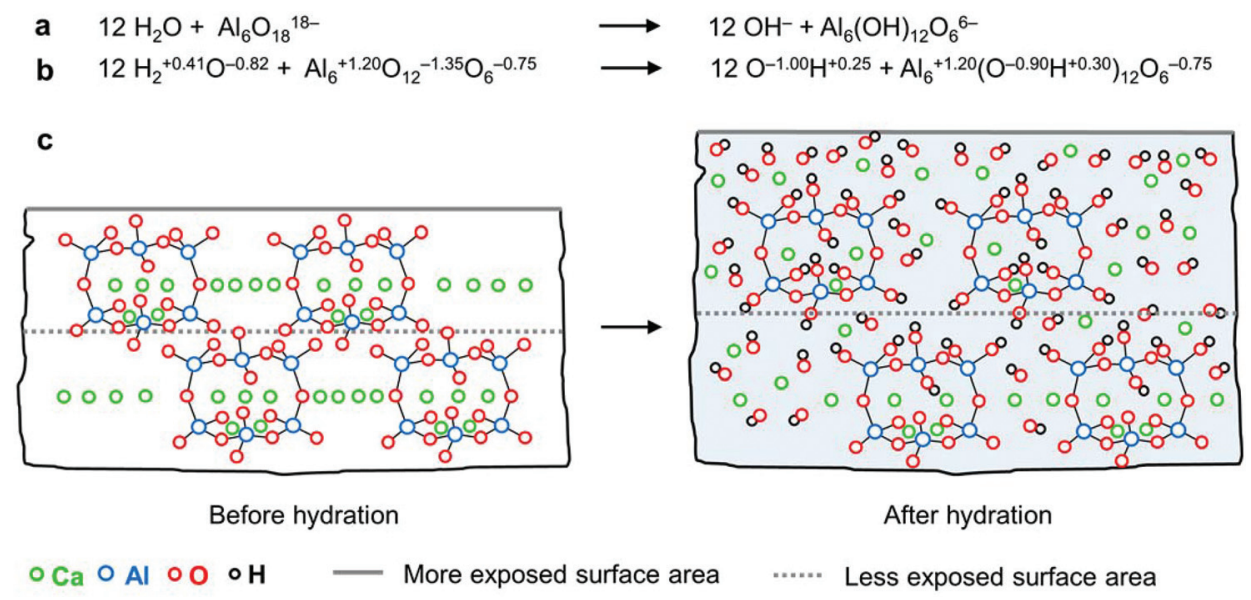

Fig. 7 Details of the initial hydration reaction of tricalcium aluminate. (a) Net reaction using formal charges. (b) Net reaction showing atomic charges that represent the balance of covalent versus ionic bonding truthfully for simulations (ref. 10 and 20). (c) Schematic of structural changes upon protonation of the first layer of aluminate rings and of the top portion of the second layer. The hydration reaction causes swelling and deposition of an amorphous layer of $\mathrm{Ca}(\mathrm{OH})_{2}$ (portlandite) on the aluminate surface.

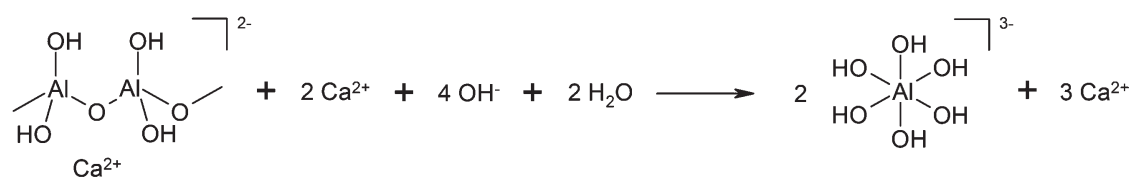

Scheme 2 Subsequent hydration of an aluminate ring fragment to octahedral aluminates such as hydrocalumite.

The aim in this contribution is modeling this very first step of the hydration reaction, which drastically changes the surface chemistry and morphology (Fig. 7). For simplicity, we assume that this process initially affects the first molecular layer as well as the top portion of the second molecular layer.

The next steps in the sequence of the hydration reaction involve the generated hydroxide ions as strong nucleophiles, which fully hydrolyze the ring structure in combination with water (Scheme 2).

The coordination number of aluminum then increases from four to six and individual $\mathrm{Al}(\mathrm{OH})_{6}$ ions eventually organize, depending on the nature and concentration of the ions present, into ettringite and layered double hydroxides, such as hydrocalumite, Friedel's salt, and monosulphate. ${ }^{37}$ Force field parameters for the simulation of these phases are available in the INTERFACE force field so that also further steps of the reaction can be investigated. ${ }^{10}$ In the present work, however, we focus on the initial hydration stage since very little information is available about the transformation at the molecular scale for each step. Full hydration in water is thus not the subject of this contribution because a cascade of reactions needs to be evaluated.

\subsection{Agglomeration of pure and initially hydrated $\mathrm{C}_{3} \mathrm{~A}$ surfaces}

Agglomeration is the reverse process of cleavage (Fig. 8 and 9). The distance dependence of the agglomeration energy shows that over $90 \%$ of recoverable attractive energy is felt at distances closer than $1 \mathrm{~nm}$, consistent with detailed analyses of similar ionic surfaces of clay minerals and tricalcium sili-

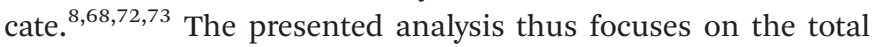
energy difference between closest contact and large separation of $20 \mathrm{~nm}$ (Fig. S2†).

Agglomeration energies of pure and hydrated $\mathrm{C}_{3} \mathrm{~A}$ surfaces are computed significantly lower than cleavage energies (Table 6). The maximum recoverable energy upon agglomeration is $860 \mathrm{~mJ} \mathrm{~m}^{-2}$, i.e., about $70 \%$ of the original cleavage energy. The agglomeration energy also decreases slightly at higher temperature similar to the cleavage energy (Table 6). The decrease amounts to $6 \pm 4 \%$ upon change in temperature from $25^{\circ} \mathrm{C}$ to $90{ }^{\circ} \mathrm{C}$. 

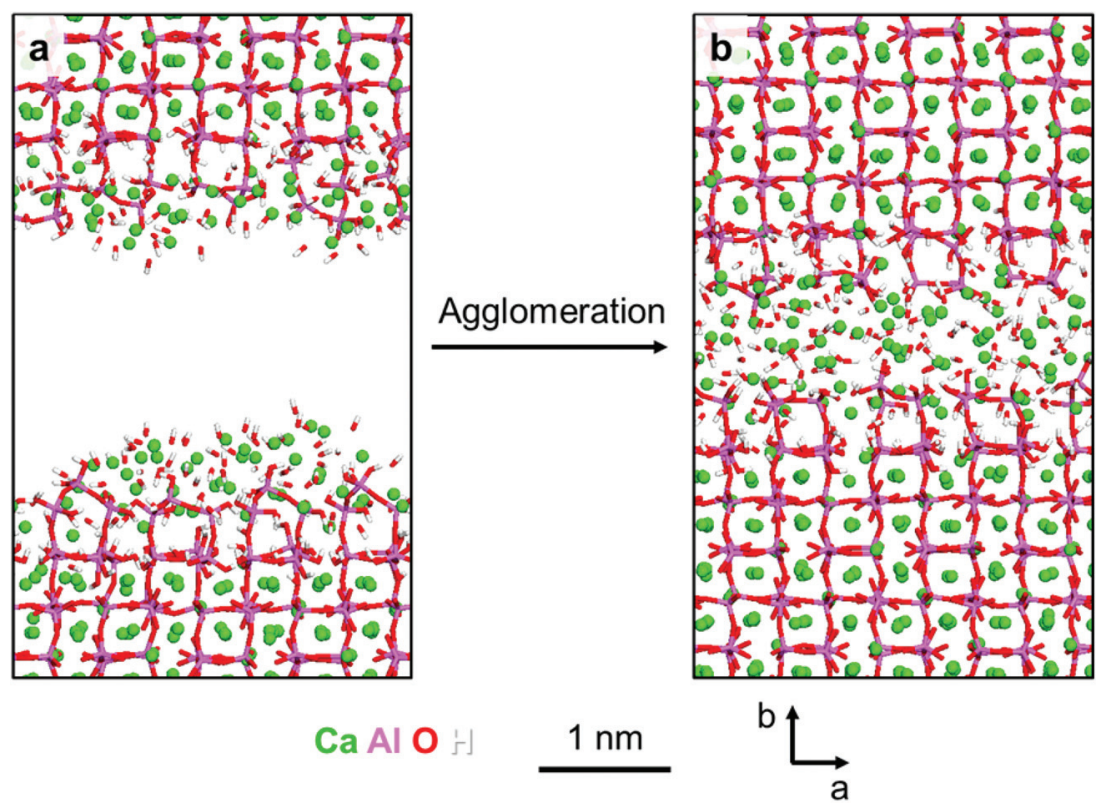

Fig. 8 Agglomeration of initially hydrated surfaces of tricalcium aluminate in air. (a) Cleaved (100) surfaces upon initial hydration in side view. (b) Agglomerated (100) surfaces upon initial hydration. An amorphous interfacial layer of calcium hydroxide can be seen.

a
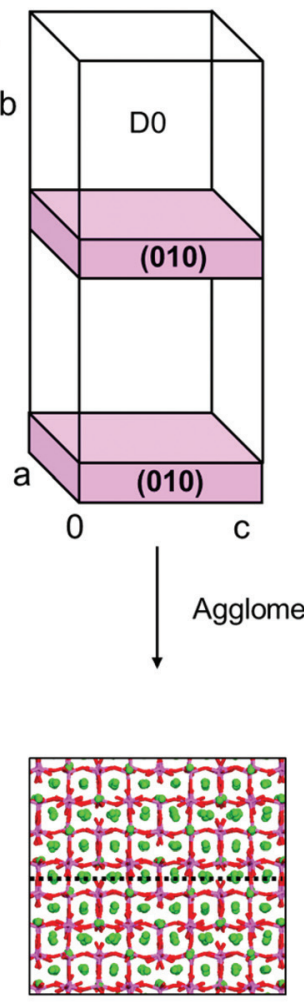

b
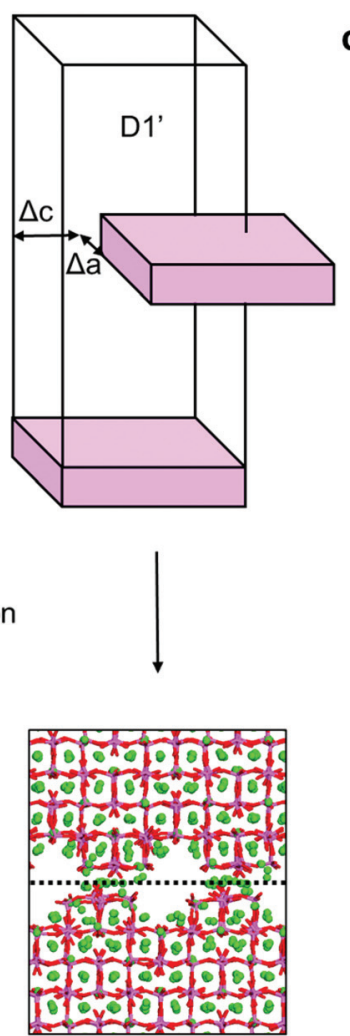

C
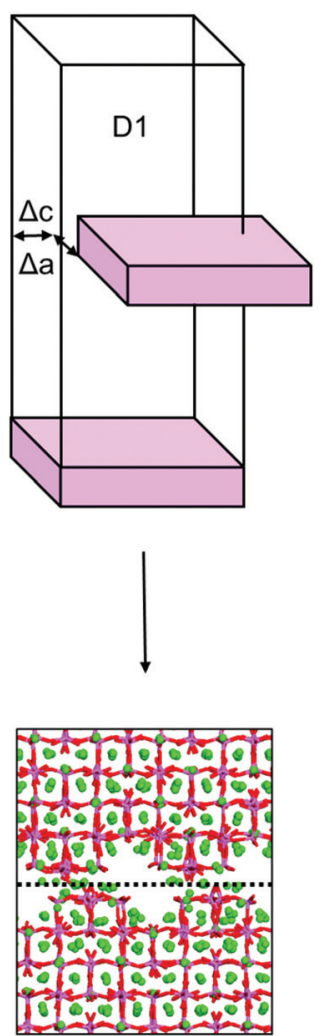

\section{Ca AlO $1 \mathrm{~nm}$}

Fig. 9 Effect of surface displacement on contact area and agglomeration energy. (a) The highest agglomeration energy is found in the absence of lateral offsets (D0). (b) Example of a horizontal displacement $\Delta a=-1.0 \mathrm{~nm}, \Delta c=1.0 \mathrm{~nm}$ of the two surfaces, which reduces agglomeration (D1'). (c) Example of another displacement $\Delta a=-1.0 \mathrm{~nm}, \Delta c=0.5 \mathrm{~nm}$, leading to even lower agglomeration (D1). The reduction in agglomeration energy correlates with the reduction in contact area of calcium ions upon surface displacement, accompanied by lower gravimetric density in the contact zone (see dotted black lines). 
Another major reduction in cohesion between the cleaved surfaces occurs upon initial hydration (Table 6). Hydrated surfaces are of lower polarity, e.g., due to $\mathrm{AlOH}$ groups instead of semi-ionic $\mathrm{Al}-\mathrm{O}$ bonds, and Coulomb interactions are thus weaker (Fig. 7). In addition, the hydrated surfaces are covered with an amorphous layer of calcium hydroxide that widens the gap between cleavage planes and mitigates attraction (Fig. 8). After initial hydration, the remaining energy of agglomeration is therefore approximately $500 \mathrm{~mJ} \mathrm{~m}^{-2}$, i.e., about $40 \%$ of the initial cleavage energy.

The fit between cleaved surfaces can further be diminished by lateral displacement (Fig. 9, Table 6). The inherent surface roughness of tricalcium aluminate, represented by step-like features every $0.8 \mathrm{~nm}$, causes a substantial reduction in cohesion as a consequence of lateral offsets of surfaces upon agglomeration, in contrast to other minerals with less surface corrugation. It is thus less probable that two surfaces of $\mathrm{C}_{3} \mathrm{~A}$ would match in surface corrugation after cleavage and increased freedom of reorientation. These effects are illustrated for three representative cases (Fig. 9a-c). An unfavorable offset alone can reduce the maximum agglomeration energy of $860 \mathrm{~mJ} \mathrm{~m}^{-2}$ to $300 \mathrm{~mJ} \mathrm{~m}^{-2}$ (Table 6). The combination of hydration and lateral displacement of surfaces after cleavage leads to a maximum reduction in agglomeration energy to $\sim 250 \mathrm{~mJ} \mathrm{~m}^{-2}$ at $90^{\circ} \mathrm{C}$, which corresponds to $\sim 20 \%$ of the original cleavage energy. Especially for real particle surfaces with imperfect cleavage planes and changing angular orientation of the surfaces after cleavage, the effects of surface displacement onto agglomeration are likely significant.

The information on nanoscale agglomeration is newly generated by the simulation and experimental measurements are currently not available for comparison. The data are expected to be about $\pm 10 \%$ accurate similar to validated cleavage energies (section 4.2) and predictions for similar minerals. ${ }^{8,10,68,72,73}$

\section{Influence of adsorbed organic thin films}

\subsection{Mechanism}

Agglomeration of the mineral surfaces undergoes drastic further changes in the presence of adsorbed organic molecules. Amino alcohols such as triisopropanol amine (TIPA), triethanol amine (TEA), MDIPA ( $N$-methyl-diisopropanolamine), and glycerine are often added during particle grinding (Scheme 3). ${ }^{2,3,8,33-35}$ A typical surface coverage of $\sim 65 \%$ of a molecular monolayer, or $0.20 \mathrm{mg} \mathrm{m}^{-2}$, of these compounds was assumed on individual cleaved surfaces in air (details in Table S1 $\dagger$ ). ${ }^{8}$ The interfacial region between two surfaces in contact with each other then contains an amount between a molecular monolayer and a molecular bilayer (130\%, Fig. 10).

The alcohol molecules are attracted to the mineral surfaces through chelation of calcium ions by hydroxyl groups and through the formation of hydrogen bonds with hydroxide ions and aluminol groups of the hydrated tricalcium aluminate. The organic layer reduces Coulomb interactions between the cleaved surfaces and thereby their cohesion (Fig. 11). It has previously been shown that layered minerals with interlayer cations require approximately $0.5 \mathrm{~nm}$ layer separation to distribute cations between the two cleaved layers and eliminate over $90 \%$ of the attractive Coulomb energy. ${ }^{8,68,72,73}$ The polar organic molecules are attracted to the surfaces and assume essentially the role of a molecular spacer of similar thickness. The reduction in agglomeration energy, however, varies significantly depending on the specific chemistry of the alcohol. Assuming no surface displacement upon cleavage, the agglomeration energy of initially hydrated surfaces is $500 \mathrm{~mJ} \mathrm{~m}^{-2}$. Most alcohols reduce the agglomeration energy to values between 100 and $60 \mathrm{~mJ} \mathrm{~m}^{-2}$ (Fig. 11). The largest reduction was observed for $N$-methyl-diisopropanolamine (MDIPA) with an agglomeration energy of only $\sim 30 \mathrm{~mJ} \mathrm{~m} \mathrm{~m}^{-2}$. Minimal agglomeration in case of MDIPA appears to be associated with a larger proportion of hydrophobic groups versus hydrophilic groups (Scheme 3) that help separate ionic groups on the two surfaces better. The benefit of molecular simulation is that molecule-specific agglomeration energies become predictable and molecular origins can be identified using visualization along with structural and thermodynamic analysis.

Once organic molecules are present, the effect of surface displacements on the agglomeration energy (Fig. 9) also becomes less significant. The reduction of surface forces between the cleaved mineral surfaces by organic inclusions diminishes energy barriers of lateral surface displacement and enables higher interfacial mobility.

\subsection{Comparison to other surfaces}

The role of similar organic modifiers has also been previously investigated on other substrates, for example, tricalcium silicate ${ }^{8}$ clay minerals, ${ }^{68,72}$ metal nanostructures, ${ }^{74,75}$ and various oxides. ${ }^{76,77}$ On tricalcium aluminate, the molecules are loosely grafted without specific chemical bonds, ionic bonds, and regular coordination patterns. The situation is similar on
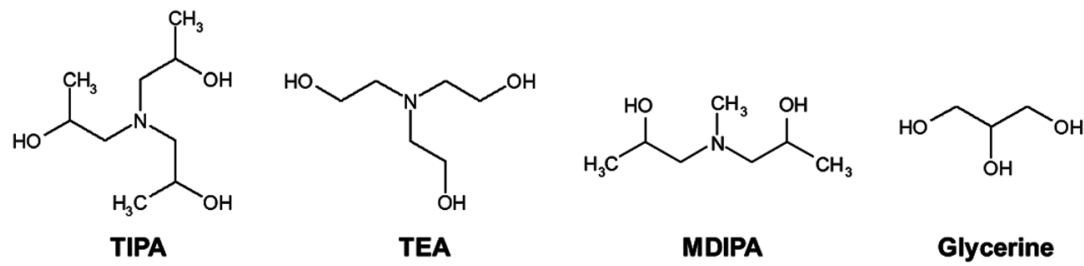

Scheme 3 Structure of triisopropanolamine (TIPA), triethanolamine (TEA), N-methyl-diisopropanolamine (MDIPA), and glycerine used as additives for grinding in cement. 

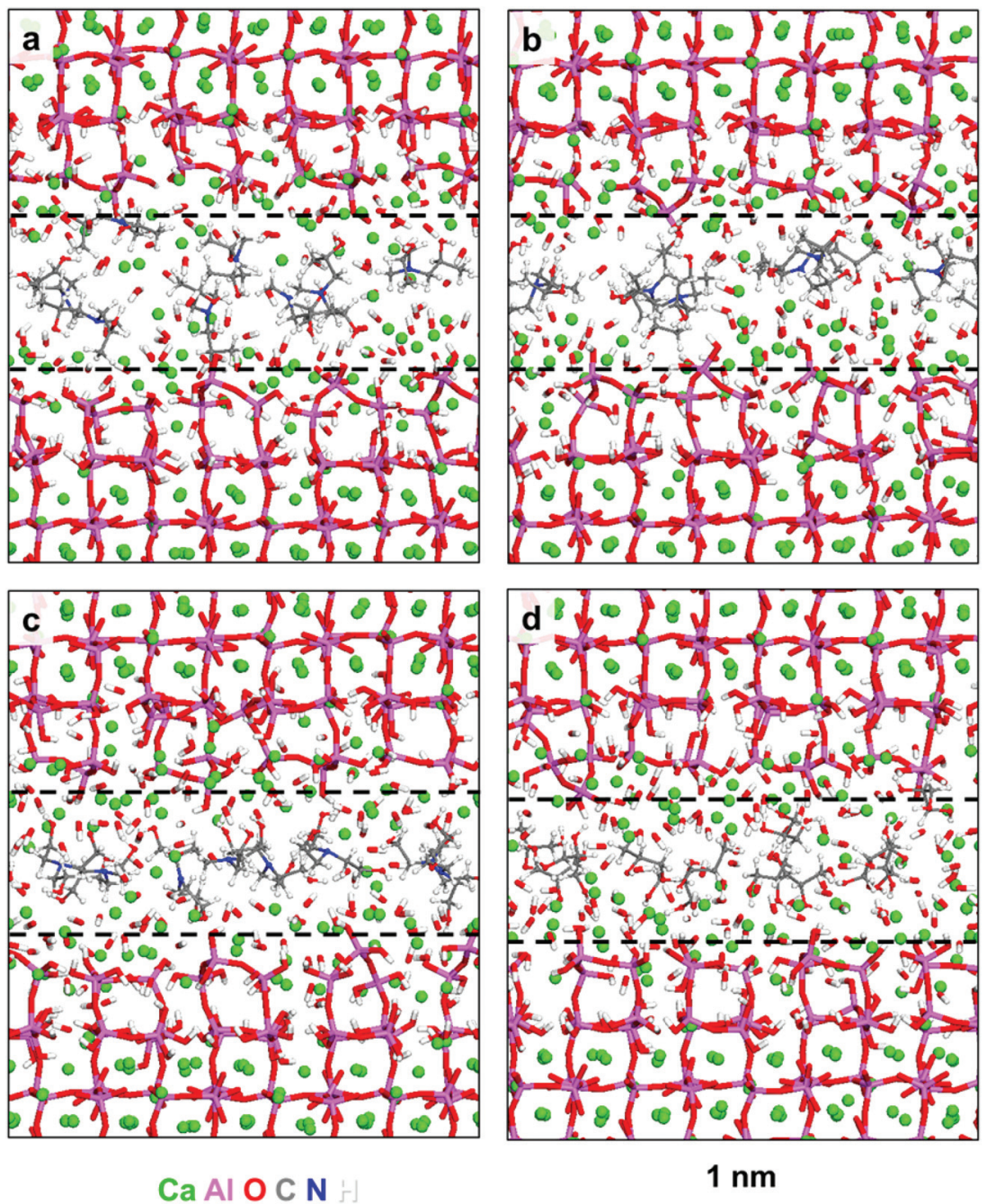

Fig. 10 Conformation of alcohol molecules confined between superficially hydrated surfaces of tricalcium aluminate according to molecular dynamics simulation. (a) MDIPA, (b) TIPA, (c) TEA, and (d) glycerine. The organic layer acts as a spacer to keep the surfaces apart and mitigates attractive polar interactions.

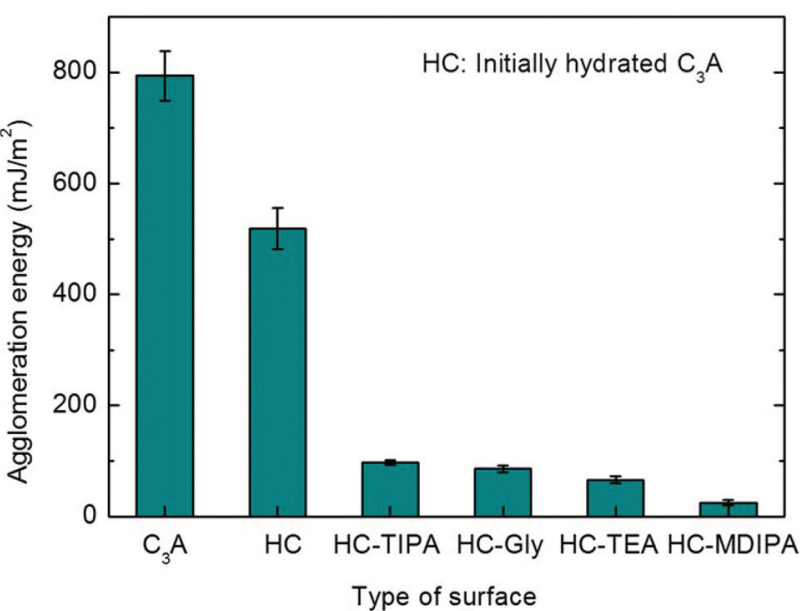

Fig. 11 Computed agglomeration energy of tricalcium aluminate modified with surface-adsorbed alcohols at $\sim 130 \%$ surface coverage at $363 \mathrm{~K}$. A decrease up to $95 \%$ is found in comparison to the initially hydrated surface $(\mathrm{HC})$. tricalcium silicate, which is the major phase with $>50 \%$ content in Portland cement (Fig. 12). On common cleavage planes of both tricalcium aluminate $\left(\mathrm{C}_{3} \mathrm{~A}\right)$ and tricalcium silicate $\left(\mathrm{C}_{3} \mathrm{~S}\right)$ at the same surface coverage, the molecules show qualitatively the same trend in reduction of the agglomeration energy, except for TIPA as an outlier.

The similar behavior on these surfaces leads to practical implications. The computed ranking of reduction in agglomeration energy on tricalcium silicate was shown to correlate with the performance in full-scale trials at cement plants. ${ }^{8}$ The force field and results for tricalcium aluminate are of the same quality. Since tricalcium aluminate $\left(\mathrm{C}_{3} \mathrm{~A}\right)$ and tricalcium silicate $\left(\mathrm{C}_{3} \mathrm{~S}\right)$ exhibit a similar trend, modeling the behavior of molecular additives on only one surface might suffice to predict the anticipated performance on both surfaces, offering a saving in time (Fig. 12). However, possibly meaningful outliers such as TIPA also need consideration. It is known that TIPA has a major effect on long-term strength development of 


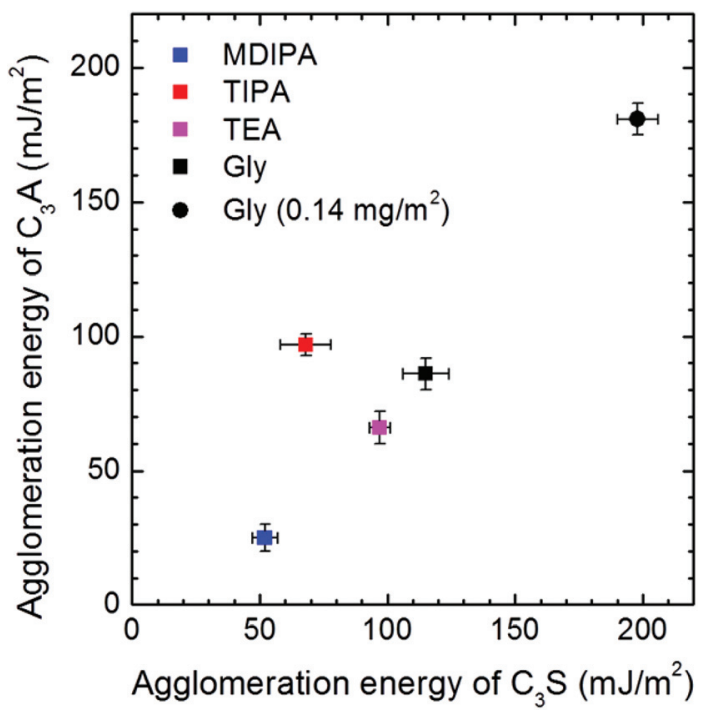

Fig. 12 Comparison of the agglomeration energy in the presence of grinding aids for superficially hydrated $C_{3} A$ and $C_{3} S$ surfaces (data for $\mathrm{C}_{3} \mathrm{~S}$ from ref. 8). With the exception of TIPA, the action of the additives is similar with a trend towards lower agglomeration energy for $C_{3} A$.

cement, and possible relations to the unexpected behavior will be examined in follow-on studies.

\subsection{Anticipated applications of the model}

This work focuses on establishing credibility of the force field and on first new insights into hydration and surface properties of tricalcium aluminate. The models for tricalcium aluminate gain particular significance in the context of the entire set of cement minerals and through full compatibility with models of the other components. ${ }^{10}$ They are thus applicable to impure phases, mixtures of minerals, hydrated systems at any stage, and polymer interfaces. Systems in aqueous solution can be explicitly investigated, and nanostructures up to $100 \mathrm{~nm}$ size upon grinding and hydration of cement, far beyond single nanocrystals, can be computationally explored. These new capabilities by simulation and comparisons to measurements by X-Ray scattering, IR, NMR, AFM, kinetic observations, and mechanical characterization can provide unprecedented insight into the assembly of molecules to nanocrystals and glassy structures. Specific newly accessible information includes the identification and visualization of structural patterns, associated energies, thermodynamic as well as kinetic properties in correlation with laboratory and building-scale observations. Understanding and control of the assembly of nanoscale building blocks into larger structures ultimately supports the development of next generation, sustainable cement materials.

\section{Conclusion}

This contribution introduces a force field for tricalcium aluminate $\left(\mathrm{C}_{3} \mathrm{~A}\right)$ and provides understanding of the initial hydration reaction, agglomeration of surfaces, and interactions with organic molecules. The force field parameters for the mineral and the partially hydrated surfaces can be applied to the study of structural, interfacial, and mechanical properties of cement at the scale of 1 to $100 \mathrm{~nm}$, and facilitate access to a range of problems that cannot be addressed by computationally expensive DFT methods. The force field reproduces atomic coordinates, elastic moduli, thermal expansion, as well as cleavage energies in excellent agreement with experimental data. The parameters are embedded in the force fields PCFF, CVFF, CHARMM, AMBER, OPLS-AA, as well as INTERFACE and can be applied to a wide range of aqueous, inorganic, organic, and biological interfaces in building materials and dental root filling cements. The simulation of impure solid solutions of $\mathrm{C}_{3} \mathrm{~A}$ and advanced hydration products is feasible using parameters for related compounds in the INTERFACE force field, and extensions to chemical reactions are possible (see section S1.9 in the ESI $\dagger$ ).

The common (001) cleavage plane in the highly symmetric $\mathrm{C}_{3} \mathrm{~A}$ crystal possesses a cleavage energy of $1260 \pm 50 \mathrm{~mJ} \mathrm{~m}^{-2}$, of which about two thirds are recoverable upon agglomeration. Lateral displacement of the corrugated surfaces and initial hydration after cleavage substantially lower the agglomeration energy, reaching values as low as $250 \mathrm{~mJ} \mathrm{~m}^{-2}$. Quantitative atomistic models of the initial hydration process were introduced, including the formation of an amorphous layer of calcium hydroxide on the mineral surface and emerging disordered morphologies. Modified interactions between the mineral surfaces significantly affect the agglomeration energy.

Adsorbed organic molecules such as alcohols and amines coordinate superficial calcium ions and form hydrogen bonds with hydroxide and aluminol groups on the hydrated surfaces. The presence of these molecules further reduces agglomeration energies. At a thickness of a partial molecular monolayer per surface (surface coverage of $65 \%$ ), corresponding to typical conditions during cement grinding in a ball mill, the agglomeration energy could be remarkably reduced to $30 \mathrm{~mJ} \mathrm{~m}^{-2}$, i.e., more than an order of magnitude compared to an initially hydrated surface. Thereby, $N$-methyldiisopropanolamine (MDIPA) showed a stronger reduction of surface forces than glycerol and other amines at the same surface coverage. The relative order of surface forces on tricalcium aluminate is similar to tricalcium silicate and suggests the possibility of predictions using a single reference surface. The force field and initial results are a step forward to understand cement hydration and the role of adsorbed organic molecules at the 1 to $100 \mathrm{~nm}$ scale. In follow-on studies, simulations may effectively monitor complex mineral phases and hydration mechanisms in the presence of organic and polymeric additives to improve specific cement properties in comparison with experiment.

\section{Acknowledgements}

The authors acknowledge support by the ACS Petroleum Research Fund (54135-ND10), the Swiss Commission for 
Technological Innovation (KTI 13703.1 PFFLR-IW), Sika Technology AG, ETH Zurich, the National Science Foundation (DMR 0955071), and the University of Akron. The allocation of computational resources at the Ohio Supercomputing Center is gratefully acknowledged.

\section{References}

1 R. J. Flatt, N. Roussel and C. R. Cheeseman, J. Eur. Ceram. Soc., 2012, 32, 2787-2798.

2 M. Katsioti, P. E. Tsakiridis, P. Giannatos, Z. Tsibouki and J. Marinos, Constr. Build. Mater., 2009, 23, 1954-1959.

3 A. Atmaca and M. Kanoglu, Energy, 2012, 42, 261-269.

4 K. L. Scrivener, Chem. World, 2008, 5, 62-66.

5 K. L. Scrivener and A. Nonat, Cem. Concr. Res., 2011, 41, 651-665.

6 D. W. Fuerstenau, K. S. Venkataraman and B. V. Velamakanni, Int. J. Miner. Process., 1985, 15, 251-267.

7 D. W. Fuerstenau and A. Z. M. Abouzeid, Int. J. Miner. Process., 2002, 67, 161-185.

8 R. K. Mishra, R. J. Flatt and H. Heinz, J. Phys. Chem. C, 2013, 117, 10417-10432.

9 M. Schneider, M. Romer, M. Tschudin and H. Bolio, Cem. Concr. Res., 2011, 41, 642-650.

10 H. Heinz, T.-J. Lin, R. K. Mishra and F. S. Emami, Langmuir, 2013, 29, 1754-1765.

11 P. M. Dove, N. Z. Han and J. J. De Yoreo, Proc. Natl. Acad. Sci. U. S. A., 2005, 102, 15357-15362.

12 P. J. McDonald, J. P. Korb, J. Mitchell and L. Monteilhet, Phys. Rev. E: Stat. Phys., Plasmas, Fluids, Relat. Interdiscip. Top., 2005, 72, 011409.

13 A. J. Allen, J. J. Thomas and H. M. Jennings, Nat. Mater., 2007, 6, 311-316.

14 I. G. Richardson, Cem. Concr. Res., 2008, 38, 137-158.

15 R. J. Flatt, I. Schober, E. Raphael, C. Plassard and E. Lesniewska, Langmuir, 2009, 25, 845-855.

16 L. B. Skinner, S. R. Chae, C. J. Benmore, H. R. Wenk and P. J. M. Monteiro, Phys. Rev. Lett., 2010, 104, 195502.

17 J. W. Bullard, H. M. Jennings, R. A. Livingston, A. Nonat, G. W. Scherer, J. S. Schweitzer, K. L. Scrivener and J. J. Thomas, Cem. Concr. Res., 2011, 41, 1208-1223.

18 B. J. Smith, A. Rawal, G. P. Funkhouser, L. R. Roberts, V. Gupta, J. N. Israelachvili and B. F. Chmelka, Proc. Natl. Acad. Sci. U. S. A., 2011, 108, 8949-8954.

19 A. G. Kalinichev and R. J. Kirkpatrick, Chem. Mater., 2002, 14, 3539-3549.

20 H. Heinz and U. W. Suter, J. Phys. Chem. B, 2004, 108, 18341-18352.

21 R. J. Pellenq, A. Kushima, R. Shahsavari, K. J. Van Vliet, M. J. Buehler, S. Yip and F. J. Ulm, Proc. Natl. Acad. Sci. U. S. A., 2009, 106, 16102-16107.

22 H. Manzano, J. S. Dolado and A. Ayuelaz, J. Am. Ceram. Soc., 2009, 92, 897-902.

23 J. S. Dolado, M. Griebel, J. Hamaekers and F. Heber, J. Mater. Chem., 2011, 21, 4445-4449.
24 S. Galmarini, A. Aimable, N. Ruffray and P. Bowen, Cem. Concr. Res., 2011, 41, 1330-1338.

25 H. Manzano, R. J. M. Pellenq, F.-J. Ulm, M. J. Buehler and A. C. T. van Duin, Langmuir, 2012, 28, 4187-4197.

26 J. Moon, S. Yoon, R. M. Wentzcovitch, S. M. Clark and P. J. M. Monteiro, J. Am. Ceram. Soc., 2012, 95, 29722978.

27 E. Masoero, E. Del Gado, R. J. M. Pellenq, F. J. Ulm and S. Yip, Phys. Rev. Lett., 2012, 109, 155503.

28 E. Durgun, H. Manzano, R. J. M. Pellenq and J. C. Grossman, Chem. Mater., 2012, 24, 1262-1267.

29 H. Heinz, R. A. Vaia, H. Koerner and B. L. Farmer, Chem. Mater., 2008, 20, 6444-6456.

30 S. V. Patwardhan, F. S. Emami, R. J. Berry, S. E. Jones, R. R. Naik, O. Deschaume, H. Heinz and C. C. Perry, J. Am. Chem. Soc., 2012, 134, 6244-6256.

31 N. Fernandez, R. Mani, D. Rinaldi, D. Kadau, M. Mosquet, H. Lombois-Burger, J. Cayer-Barrioz, H. J. Herrmann, N. D. Spencer and L. Isa, Phys. Rev. Lett., 2013, 111, 108301. 32 D. P. Bentz, J. Am. Ceram. Soc., 1997, 80, 3-21.

33 F. G. Serafin, Amide Grinding Aid, U.S. Patent, 3,459,570, August 5, 1969.

34 S. Sohoni, R. Sridhar and G. Mandal, Powder Technol., 1991, 67, 277-286.

35 B. Marazzani, C. Kurz, C. Burge and T. Muller, Dialkanolamine als Additive zum Mahlen von Feststoffen, European Patent, 2,527,307 A1, November 28, 2012.

36 M. Torabinejad and N. Chivian, J. Endod, 1999, 25, 197205.

37 H. F. W. Taylor, Cement Chemistry, Academic Press, London, 1997.

38 L. Black, C. Breen, J. Yarwood, C. S. Deng, J. Phipps and G. Maitland, J. Mater. Chem., 2006, 16, 1263-1272.

39 H. Minard, S. Garrault, L. Regnaud and A. Nonat, Cem. Concr. Res., 2007, 37, 1418-1426.

40 S. H. Oh, R. Finones, S. Jin, S. Y. Choi and K. N. Kim, J. Mater. Res., 2004, 19, 1062-1067.

41 W. Liu, W. Peng, Y. Zhu and J. Chang, J. Biomed. Mater. Res., Part B, 2012, 100B, 1257-1263.

42 F. C. Lee, H. M. Banda and F. P. Glasser, Cem. Concr. Res., 1982, 12, 237-246.

43 K. Fukuda, S. Inoue and H. Yoshida, J. Am. Ceram. Soc., 2003, 86, 112-114.

44 S. L. Meyers, J. Ind. Eng. Chem., 1940, 32, 1107-1112.

45 R. A. Schroeder and L. L. Lyons, J. Inorg. Nucl. Chem., 1966, 28, 1155-1163.

46 P. Tarte, Spectrochim. Acta, Part A, 1967, 23, 2127-2143.

47 S. N. Ghosh and A. K. Chatterjee, J. Mater. Sci., 1974, 9, 1577-1584.

48 P. Mondal and J. W. Jeffery, Acta Crystallogr., Sect. B: Struct. Sci., 1975, 31, 689-697.

49 T. L. Hughes, C. M. Methven, T. G. J. Jones, S. E. Pelham, P. Fletcher and C. Hall, Adv. Cem. Based Mater., 1995, 2, 91-104.

50 K. Velez, S. Maximilien, D. Damidot, G. Fantozzi and F. Sorrentino, Cem. Concr. Res., 2001, 31, 555-561. 
51 L. Fernández-Carrasco, D. Torrens-Martín, L. M. Morales and S. Martínez-Ramírez, in Infrared Spectroscopy - Materials Science, Engineering and Technology, ed. T. Theophanides, InTech Press, 2012, ch. 19, http://www.intechopen.com.

52 S. Brunauer, D. L. Kantro and C. H. Weise, Can. J. Chem., 1956, 34, 729-742.

53 H. Heinz, H. J. Castelijns and U. W. Suter, J. Am. Chem. Soc., 2003, 125, 9500-9510.

54 H. Heinz, H. Koerner, K. L. Anderson, R. A. Vaia and B. L. Farmer, Chem. Mater., 2005, 17, 5658-5669.

55 H. Heinz, R. A. Vaia, B. L. Farmer and R. R. Naik, J. Phys. Chem. C, 2008, 112, 17281-17290.

56 H. Sun, J. Comput. Chem., 1994, 15, 752-768.

57 H. Sun, S. J. Mumby, J. R. Maple and A. T. Hagler, J. Am. Chem. Soc., 1994, 116, 2978-2987.

58 H. Sun, Macromolecules, 1995, 28, 701-712.

59 H. Sun, J. Phys. Chem. B, 1998, 102, 7338-7364.

60 A. D. MacKerell, D. Bashford, M. Bellott, R. L. Dunbrack, J. D. Evanseck, M. J. Field, S. Fischer, J. Gao, H. Guo, S. Ha, D. Joseph-McCarthy, L. Kuchnir, K. Kuczera, F. T. K. Lau, C. Mattos, S. Michnick, T. Ngo, D. T. Nguyen, B. Prodhom, W. E. Reiher, B. Roux, M. Schlenkrich, J. C. Smith, R. Stote, J. Straub, M. Watanabe, J. Wiorkiewicz-Kuczera, D. Yin and M. Karplus, J. Phys. Chem. B, 1998, 102, 3586-3616.

61 D. A. Pearlman, D. A. Case, J. W. Caldwell, W. S. Ross, T. E. Cheatham, S. Debolt, D. Ferguson, G. Seibel and P. Kollman, Comput. Phys. Commun., 1995, 91, 1-41.

62 W. L. Jorgensen, D. S. Maxwell and J. TiradoRives, J. Am. Chem. Soc., 1996, 118, 11225-11236.
63 P. Dauber-Osguthorpe, V. A. Roberts, D. J. Osguthorpe, J. Wolff, M. Genest and A. T. Hagler, Proteins: Struct., Funct., Genet., 1988, 4, 31-47.

64 J. M. Wang, R. M. Wolf, J. W. Caldwell, P. A. Kollman and D. A. Case, J. Comput. Chem., 2004, 25, 1157-1174.

65 S. S. Batsanov, Inorg. Mater., 2001, 37, 871-885.

66 H. Heinz, R. A. Vaia, B. L. Farmer and R. R. Naik, J. Phys. Chem. C, 2008, 112, 17281-17290.

67 V. L. Burdick and D. E. Day, J. Am. Ceram. Soc., 1967, 50, 97-101.

68 H. Heinz, R. A. Vaia and B. L. Farmer, J. Chem. Phys., 2006, 124, 224713.

69 G. D. Zartman, H. Liu, B. Akdim, R. Pachter and H. Heinz, J. Phys. Chem. C, 2010, 114, 1763-1772.

70 Y. T. Fu, G. D. Zartman, M. Yoonessi, L. F. Drummy and H. Heinz, J. Phys. Chem. C, 2011, 115, 22292-22300.

71 C. E. Powell and G. W. Beall, Curr. Opin. Solid State Mater. Sci., 2006, 10, 73-80.

72 Y. T. Fu and H. Heinz, Chem. Mater., 2010, 22, 1595-1605.

73 Y. T. Fu and H. Heinz, Philos. Mag., 2010, 90, 24152424.

74 J. Feng, J. M. Slocik, M. Sarikaya, R. R. Naik, B. L. Farmer and H. Heinz, Small, 2012, 8, 1049-1059.

75 K. C. Jha, H. Liu, M. R. Bockstaller and H. Heinz, J. Phys. Chem. C, 2013, 117, 25969-25981.

76 L. H. Dubois and R. G. Nuzzo, Annu. Rev. Phys. Chem., 1992, 43, 437-463.

77 H. Heinz, R. A. Vaia and B. L. Farmer, Langmuir, 2008, 24, 3727-3733. 